\title{
ANALYSIS OF DESIGN EFFECT FOR INDONESIAN NATIONAL LABOUR FORCE SURVEY*
}

\author{
Adhi Kurniawan \\ BPS-Statistics Indonesia, adhikurnia22@gmail.com \\ Indonesian Journal of Statistics and Its Applications (elSSN:2599-0802) \\ Vol 4 No 3 (2020), 462 - 473 \\ Copyright () 2020 Adhi Kurniawan. This is an open-access article distributed under the Creative \\ Commons Attribution License, which permits unrestricted use, distribution, and reproduction in any
} medium, provided the original work is properly cited.

\begin{abstract}
The implementation of multistage sampling design is a good strategy to achieve the gain in efficiency of survey cost. However, in terms of sampling efficiency, it leads to the loss of precision indicated by the higher sampling variance compared to SRS design. Design effect measures the ratio of actual variance to the variance of SRS and can be decomposed to the effect of sample weight and the effect of clustering. This study aims to analyse the effect of sample weight and the effect of clustering on the estimation of labour variables resulted from the National labour Force Survey of Indonesia. The analysis is provided at the national level, stratum level, and province level. In general, the study finds that the design effect varies between labour variables. The effect of clustering is higher than the effect of the sample weight. There is also a high variability of the clustering effect between provinces and between strata (urban-rural). In contrast, the design effect due to the sample weight is similar between provinces, but it differs between strata. Allocating sample size proportionally to each stratum could be a good strategy for dealing with the high effect of weighting. On the other hand, for the future specific survey that measures the variable with a high clustering effect and high rate of homogeneity, the alternative strategy is increasing the sample size of the cluster and declining the sample size of households per cluster.
\end{abstract}

Keywords: clustering effect, rate of homogeneity, weighting effect.

\section{Introduction}

Complex survey design is commonly implemented in the large-scale survey, particularly household surveys conducted by the National Statistical Office. In general,

" Received May 2020; Accepted Nov 2020; Published online on Nov 2020 
complex design applies clustering or multistage sampling to improve the feasibility of data collection, in terms of maximizing the efficiency of fieldwork management and survey cost. However, this procedure tends to result in higher sampling variance compared to simple random sampling so that it is not appropriate to use simple variance estimation to assess the precision of survey estimates. Using simple formula leads to underestimated sampling variance. Therefore, the estimation for complex design has to take account the sampling design components, such as stratification, clustering, and sample weighting. These components contribute to the resulting sampling variance of complex sample estimates.

Generally, the purpose of stratification is to increase the precision of survey estimates by dividing population units to several subpopulations called strata, and then a number of samples are selected independently from population units in each strata. Homogenous units within strata will reduce the sampling variance. On the contrary, clustering refers to the process of dividing population units to a number of groups called cluster where clusters are used as sampling units. The purpose of clustering is to make the process of data collection more convenient and to reduce the survey cost by concentrating sample units that must be observed in the data collection only located at selected clusters. In addition, in complex design, sample is often selected with unequal sampling probability method such as Probability Proportional to Size (PPS) so that weighting process is required to make generalization for estimating the parameter of population. While stratification can lead to gain in precision, clustering and unequal weighting tend to increase the sampling variance.

The effect of complex sampling design to the sampling variance could be measured by design effect. In principle, design effect measures the ratio of sampling variance between complex sample and simple random sample. As an illustrative example, design effect that is equal to 2 means that the variance of complex sample is twice as high as the variance of simple random sample. Design effect can vary depending on the variable we estimate. Overall, the information regarding design effect of each survey estimates is very beneficial not only to evaluate the sampling efficiency of survey design that has been implemented, but also to design the sampling method for future survey.

The previous study had been conducted by Petterson and Silva (2005) regarding the comparison of design effect analysis for several household socio-economic surveys among 7 developing countries: Lao, Cambodia, Namibia, Vietnam, Lesotho, Republic of South Africa, and Brazil. This study found that there is dissimilarities in terms of the range of design effect between countries (Pettersson \& Silva, 2005). It is a tendency that the particular condition of population in each country has predominant effect in determining the magnitude of the rate of homogeneity. They suggested not to use the assumption of design effect and rate of homogeneity in the same survey from another country when designing the survey in different country.

The studies of design effect analysis was also conducted using Demographic Health Survey (DHS) data. These studies involved the analysis of sampling error in 48 DHS survey conducted from 1985 to 1993 . The variation of the rate of homogeneity values across countries is also high, even though considerably less than across variables (Verma \& Lê, 1996). It seems that the rate of homogeneity for demographic variables are more consistent across region than that for socioeconomic variables 
(Pettersson \& Silva, 2005).

Considering these findings, it is very important to also examine the pattern of the rate of homogeneity for labour variables. We use Indonesia National Labour Survey to investigate this pattern. The main question of this study is whether the pattern of the rate of homogeneity for labour variables between provinces in Indonesia is similar or not. Therefore, in addition to urban-rural comparison, the variation of the rate of homogeneity between provinces need to be analysed to examine the similarity/dissimilarity of the rate of homogeneity pattern.

In Indonesia, National Labour Force Survey (Sakernas) is one of the important survey that is conducted regularly, usually twice a year. This survey aims to provide labour statistical data and produce essential labour statistic indicator, such as employment rate and labour force participation rate, to measure and to evaluate the progress of social and economic development. The accuracy of statistical data resulted from this survey is predominant factor so that the reliability of survey estimates must be guaranteed. Evaluation with regard to survey design should be done regularly. Information about the precision of estimates from previous surveys can be utilized to improve the sampling design for the future survey.

In addition to estimating the point estimates of labour indicators, assessing the effect of survey design to the survey estimates should be concerned. Hence, this paper will provide the analysis of design effect, in particular for several variables resulted from National Labour Survey. More specifically, the analysis will focus on assessing the effect of weighting and the effect of clustering to the loss of precision of survey estimates. The objectives of this study are: (1) examining the variation of design effect among labour variables, (2) analysing the difference of weighting and clustering effect between urban area and rural area, (3) investigating the difference of design effect among variables for domain estimation at province level, (4) estimating the rate of homogeneity for several labour variables.

\section{Methods}

Literally, design effect is defined as the ratio of the actual variance of the sample to the variance of simple random sample of the same number of sample size (Kish, 1995). Hence, the design effect of the same variable resulted from two different surveys can be different although these two surveys might produce the same/similar estimate of population parameter. For example, proportion of people with primary education of National Labour Survey (Sakernas) might be relatively similar to that of National Socioeconomic Survey (Susenas). However, the design effect of that variable between these two surveys can be different. Hence, the design effect involves both the sampling efficiency of the survey design and the sampling efficiency of the estimator (Park \& Lee, 2006).

In general, the formula of design effect of survey design $p$ to estimate $\theta$ is written as

$$
\operatorname{Deff}_{p}(\hat{\theta})=\frac{V_{p}(\hat{\theta})}{V_{\text {srs }}(\hat{\theta})}
$$

where $V_{p}(\hat{\theta})$ is the actual variance of sample based on survey design $p$ and $V_{s r s}(\hat{\theta})$ is the variance of simple random sample. 
The decomposition of design effect into three components can be denoted as

$$
\operatorname{Deff}_{p}(\hat{\theta})=\left(d_{W}(\hat{\theta}) \times d_{U}(\hat{\theta}) \times d_{X}(\hat{\theta})\right)^{2}
$$

where $d_{W}(\hat{\theta})$ is the effect of sample weights, $d_{U}(\hat{\theta})$ is the effect of clustering of analytical units into the ultimate sampling units (for example, clustering of individuals in households where they live in), and $d_{X}(\hat{\theta})$ refers to the effect of clustering, stratification, and other survey design complexities. In practice, estimating design effect using equation (2) requires more complex calculation and indirect method such as Jackknife Repeated Replication (JRR) method especially for estimating the effect of clustering, stratification, and other survey design complexities (Mecatti, 2014).

For simplification and general approximation, design effect can be decomposed into two general components: (1) effect of sample weight and (2) effect of clustering (Kalton et al., 2005). The effect of sample weight measures the effect of unequal weight to sampling variance. The unequal sampling weight due to disproportionate stratification and unequal sample selection leads to the rise of sampling variance. In general, when the sampling weight is uncorrelated to the variable of interest, the estimate of design effect due to the unequal sample weight is denoted as

$$
\mathrm{d}_{W}^{2}(\hat{\theta})=\frac{n \sum_{i} W_{i}^{2}}{\left(\sum_{i} W_{i}\right)^{2}}=1+C V_{W}^{2}
$$

where $W_{i}$ is the sample weight of $i$-th unit and $C V_{W}$ is the coefficient of variation of sample weight.

The magnitude of design effect due to the clustering depends on the number of unit per cluster and rate of homogeneity (intra-cluster correlation coefficient). The larger the number of unit selected per cluster, the larger design effect, provided that the sample size is constant. Similarly, the higher the rate of homogeneity, the higher design effect will be resulted. If a particular variable has high rate of homogeneity, the number of unit selected per cluster should be small and the sample size of cluster should be large in order to lowering the effect of clustering.

As a general formula in one stage equal cluster sampling, design effect is defined as:

$$
\mathrm{d}_{C L}{ }^{2}(\hat{\theta})=\frac{N M_{0}-1}{M_{0}(N-1)}\left\{1+\left(M_{0}-1\right) \rho\right\} \approx 1+\left(M_{0}-1\right) \rho
$$

where $M_{0}$ is the number of population unit per cluster, $N$ is the number of cluster in the population, and $\rho$ is the rate of homogeneity (Cochran \& William, 1977).

In the case of more complex design, for instance where the cluster size is unequal, stratification is included in the survey design, and the sample selection consists of more than one stage (multistage sampling), the design effect due to clustering can be approximated by:

$$
\mathrm{d}_{C L}{ }^{2}(\hat{\theta})=1+(\bar{m}-1) \bar{\rho}
$$

where $\bar{m}$ is the weighted average of the number of unit per cluster (Verma et al., $1980)$ and $\bar{\rho}$ is the average within stratum rate of homogeneity, given that the homogeneity within stratum is approximately of the same magnitude (Kalton, 1979). 


\section{Data and Variables}

The design effect is estimated using several variables from 2018 National Labour Force Survey (Sakernas). Every year, Sakernas is conducted twice: in February (for province level estimation) and in August (for district/municipality level estimation). This study uses the dataset from Sakernas February 2018. A total of 181,654 individuals in the dataset is included in the analysis. The estimation of design effect is not only analysed at national level, but also at stratum level and province level.

The study is concentrated on analysing the design effect for estimating proportion. The estimates of labour variables included for analysis are: (1) proportion of people ages $15+$ working minimum at 1 hour per day during a week, (2) proportion of people ages $15+$ who is temporary not working, (3) proportion of people ages $15+$ seeking for job, (4) proportion of people ages 15+ preparing for entrepreneurship, (5) proportion of people ages $15+$ using internet for working activities, (6) proportion of people ages 15+ having health insurance, (7) proportion of people ages 15+ having working safety insurance, and (8) proportion of people ages 15+ having additional job.

Two stage stratified sampling is implemented as the survey design of Sakernas. Urban-rural classification is used as stratifying criteria. In the first stage, a sample of census block is selected using Probability Proportional to Size (PPS) sampling, and then, in the second stage we select 10 households in each selected census block using systematic sampling. The size of sample selection in the first stage is the number of household per census block in the sampling frame, whereas the household population in the second stage of sample selection is obtained through listing (updating) process in the selected census block.

In terms of sample weight construction, it involves several steps. In the first step, we calculated the design weight or initial weight. This weight is calculated as the inverse of overall inclusion probabilities based on the targeted sample size. After data collection, design weight is corrected by considering the level of response rate and coverage error of household listing. This adjusted weight, then, is calibrated using ratio estimation method using population projection data as the benchmark population. The correction factor used in every step of adjustments leads to the increase of sample weight variation between analytical units. Mathematically, the calculation of sample weight can be defined as

$$
W_{h i j k}=W_{h i j}^{(D)} \times c f^{(n r)} \times c f^{(n c)} \times c f^{(p)}=\frac{M_{h} M_{h i}^{(u p)}}{n_{h} M_{h i} m} \times c f^{(n r)} \times c f^{(n c)} \times c f^{(p)}
$$

where

$W_{h i j} \quad$ : sampling weight for $k$-th person, $j$-th household, $i$-th cluster, and $h$-th stratum, in a particular province;

$W_{h i j}^{(D)}$ : design (initial) weight;

$M_{h} \quad$ : the number of household population from sampling frame in $h$-th stratum in a particular province;

$M_{h i} \quad$ : the number of household population from sampling frame in $i$-th cluster, $h$-th stratum, in a particular province;

$M_{h i}^{(u p)}$ : the number of household population from listing in $i$-th cluster, $h$-th stratum, in a particular province; 
$n_{h} \quad$ : the sample size of cluster in $h$-th stratum in a particular province; $m:$ the sample size of household per cluster $(m=10)$;

$c f^{(n r)}$ : correction factor for non-response adjustment;

$c f^{(n c)}$ : correction factor for household non-coverage adjustment;

$c f^{(p)}$ : correction factor for the total population by gender, age group, and urban-

rural, based on Population Projection data.

These weighting procedure leads to the unequal weight between sampling unit. Therefore, the effect of sample weight matters in the case of Sakernas data.

\section{Results}

The analysis of design effect generally consists of three main issues: (1) the effect of sample weight, (2) the effect of clustering, (3) using design effect for designing the future survey.

\subsection{Effect of sample weight}

Design effect due to the sample weight is shown by Table 1. The mean of sample weight in urban area is 1.44 larger than that in rural area. This higher mean in urban area means that on average, the sample unit in urban area represents the higher number of population than in rural area. It might be caused by several factor, such as the unequal probability sample selection, the disproportionate sample allocation between urban and rural area, and the higher correction factor used for adjustment in urban area compared to in rural area. Table 1 shows that Sakernas uses disproportionate allocation between urban rural where in urban area the proportion of population are $55 \%$, whereas there is only $47 \%$ sample allocated to urban area.

Table 1: Effect of sample weight, split by urban-rural classification

\begin{tabular}{lccrrrr}
\hline \multirow{2}{*}{ Domain } & Total & Total & \multicolumn{4}{c}{ Sample weight } \\
\cline { 4 - 7 } & population & sample & Mean & SD & CV & Deff $_{w}$ \\
\hline Urban & $55 \%$ & $47 \%$ & 1741.46 & 1210.86 & 0.70 & 1.48 \\
Rural & $45 \%$ & $53 \%$ & 1207.83 & 788.18 & 0.65 & 1.43 \\
National & $100 \%$ & $100 \%$ & 1453.15 & 1039.42 & 0.72 & 1.51 \\
\hline
\end{tabular}

The coefficient of variation of sample weight in urban area is 0.70 , while in rural area, the coefficient of variation of that is 0.65 . Therefore, the effect of weighting to design effect in urban area is also larger than in rural area (1.48 and 1.43, respectively). At national level, the design effect due to sample weight is 1.51 , higher than the design effect by urban-rural classification. It indicates that the variability of sample weight within stratum is lower than the variability of sample weight between strata. Allocating sample size proportionally to urban-rural stratum can be alternative strategy to reduce the variability of sample weight between strata so that the effect of sample weight for estimation at national level will be smaller. 
Table 2: Effect of sample weight, split by province

\begin{tabular}{lrrrr}
\hline \multirow{2}{*}{ Province } & \multicolumn{4}{c}{ Sample weight } \\
\cline { 2 - 5 } & Mean & SD & CV & Deff $_{w}$ \\
\hline Aceh & 743 & 221 & 0.30 & 1.09 \\
Sumatera Utara & 1,207 & 345 & 0.29 & 1.08 \\
Sumatera Barat & 819 & 204 & 0.25 & 1.06 \\
Riau & 1,438 & 351 & 0.24 & 1.06 \\
Jambi & 968 & 272 & 0.28 & 1.08 \\
Sumatera Selatan & 1,419 & 275 & 0.19 & 1.04 \\
Bengkulu & 677 & 163 & 0.24 & 1.06 \\
Lampung & 1,492 & 396 & 0.27 & 1.07 \\
Kepulauan Bangka Belitung & 688 & 136 & 0.20 & 1.04 \\
Kepulauan Riau & 1,066 & 826 & 0.78 & 1.60 \\
DKI Jakarta & 3,586 & 847 & 0.24 & 1.06 \\
Jawa Barat & 3,667 & 988 & 0.27 & 1.07 \\
Jawa Tengah & 2,194 & 485 & 0.22 & 1.05 \\
D.I. Yogyakarta & 1,852 & 617 & 0.33 & 1.11 \\
Jawa Timur & 2,352 & 442 & 0.19 & 1.04 \\
Banten & 3,033 & 735 & 0.24 & 1.06 \\
Bali & 1,183 & 323 & 0.27 & 1.07 \\
NTB & 1,382 & 279 & 0.20 & 1.04 \\
NTT & 694 & 169 & 0.24 & 1.06 \\
Kalimantan Barat & 953 & 247 & 0.26 & 1.07 \\
Kalimantan Tengah & 640 & 146 & 0.23 & 1.05 \\
Kalimantan Selatan & 1,022 & 209 & 0.20 & 1.04 \\
Kalimantan Timur & 1,084 & 392 & 0.36 & 1.13 \\
Kalimantan Utara & 612 & 431 & 0.70 & 1.50 \\
Sulawesi Utara & 555 & 166 & 0.30 & 1.09 \\
Sulawesi Tengah & 776 & 179 & 0.23 & 1.05 \\
Sulawesi Selatan & 965 & 189 & 0.20 & 1.04 \\
Sulawesi Tenggara & 669 & 132 & 0.20 & 1.04 \\
Gorontalo & 616 & 212 & 0.34 & 1.12 \\
Sulawesi Barat & 776 & 200 & 0.26 & 1.07 \\
Maluku & 495 & 133 & 0.27 & 1.07 \\
Maluku Utara & 463 & 164 & 0.35 & 1.13 \\
Papua Barat & 365 & 111 & 0.30 & 1.09 \\
Papua & 415 & 152 & 0.37 & 1.13 \\
\hline & & & &
\end{tabular}

If we summarize the sample weight by province as shown in Table 2, we obtain the smaller variation of weight within province. The increase of sampling variance due to sample weight in most of province is less than $10 \%$ compared to equal probability sample design. Overall, the effect of weighting for province level estimation is relatively small, except in Kepulauan Riau (1.60) and in Kalimantan Utara (1.50). However, there is a high variation of the mean of sample weight between provinces. Provinces with large population number tend to get high sample weight.

It is obvious that the effect of weighting to the increase of variance is smaller if we provide the estimation in the smaller domain. The design effect due to the sample weight for province level estimation is lower than that for urban-rural estimation, and 
the effect of weighting will be higher when we estimate at national level. Compared to the variation of sample weight within province, the variation between provinces has the higher contribution to the variation of sample weight at national level.

In practice, it is acceptable to have high variability of sample weight between provinces since province is the domain estimation. Due to the large number of province in Indonesia, the high variability of population number across provinces, and the constraint of survey costs, it is very difficult to achieve the perfect proportionate sample by province. Proportionate sample by province will require a very large sample size if we want to have province as domain estimation.

The improvement for the future survey should be focused on the enhancement of the listing quality and data collection, especially in the provinces with the high value of sample weight effect. The purpose of this data collection improvement is to reduce non-coverage error (household and people) and non-response error. Thus, the correction factor for the adjustment of sample weight can be minimized so that the effect of sample weight will be smaller.

\subsection{Effect of clustering}

Considering that the overall design effect can be defined as the multiplication between design effect due to the sample and the design effect due to clustering, we can estimate the effect of clustering by dividing the overall design effect and the effect of sample weight. The overall design effect can be directly obtained from statistical software, such as STATA, SAS, R, etc.

Table 3: Effect of clustering, split by urban-rural classification

\begin{tabular}{|c|c|c|c|c|c|c|c|}
\hline \multirow{2}{*}{ No } & \multirow{2}{*}{ Variable } & \multicolumn{3}{|c|}{$\operatorname{Deff}_{c 1}$} & \multicolumn{3}{|c|}{ Rate of homogeneity $(\rho)$} \\
\hline & & urban & rural & national & urban & rural & national \\
\hline 1 & Working & 1.60 & 1.42 & 1.47 & 0.067 & 0.047 & 0.053 \\
\hline 2 & Temporary not working & 1.25 & 1.17 & 1.17 & 0.028 & 0.019 & 0.019 \\
\hline 3 & Looking for job & 1.92 & 1.77 & 1.80 & 0.102 & 0.085 & 0.089 \\
\hline 4 & $\begin{array}{l}\text { Preparing for } \\
\text { entrepreneurship }\end{array}$ & 2.29 & 1.35 & 1.94 & 0.143 & 0.039 & 0.104 \\
\hline 5 & Using internet for working & 5.04 & 2.56 & 4.14 & 0.449 & 0.173 & 0.349 \\
\hline 6 & Having health insurance & 2.88 & 1.84 & 2.47 & 0.208 & 0.093 & 0.164 \\
\hline 7 & $\begin{array}{l}\text { Having work accident } \\
\text { insurance }\end{array}$ & 2.94 & 1.90 & 2.55 & 0.216 & 0.100 & 0.172 \\
\hline 8 & Having additional job & 2.08 & 2.21 & 2.03 & 0.120 & 0.134 & 0.115 \\
\hline
\end{tabular}

Table 3 shows that for national level, the design effect due to clustering varies between 1.17 and 4.14 and the rate of homogeneity is between 0.019 and 0.349 . The rate of homogeneity for all eight variables are positive indicating that the labour characteristics within cluster (census block) tend to be homogenous. The homogeneity within census block in urban area are higher than that in rural area. It means that when we design a survey for estimating labour variables, the required sample size in urban area should be larger than the sample size in rural area.

Using internet for working is the variable with the highest rate of homogeneity 
(0.349). The design effect due to clustering of this variable for national level is 4.14. Thus, if we want to design a specific survey about the use of internet for working activities at national level using the same/similar sampling design as Sakernas, the required sample size is roughly 4.14 times the number of sample of simple random sampling assuming that the sample is drawn randomly using equal probability selection method $\left(\right.$ Deff $\left._{\mathrm{W}}=1\right)$.

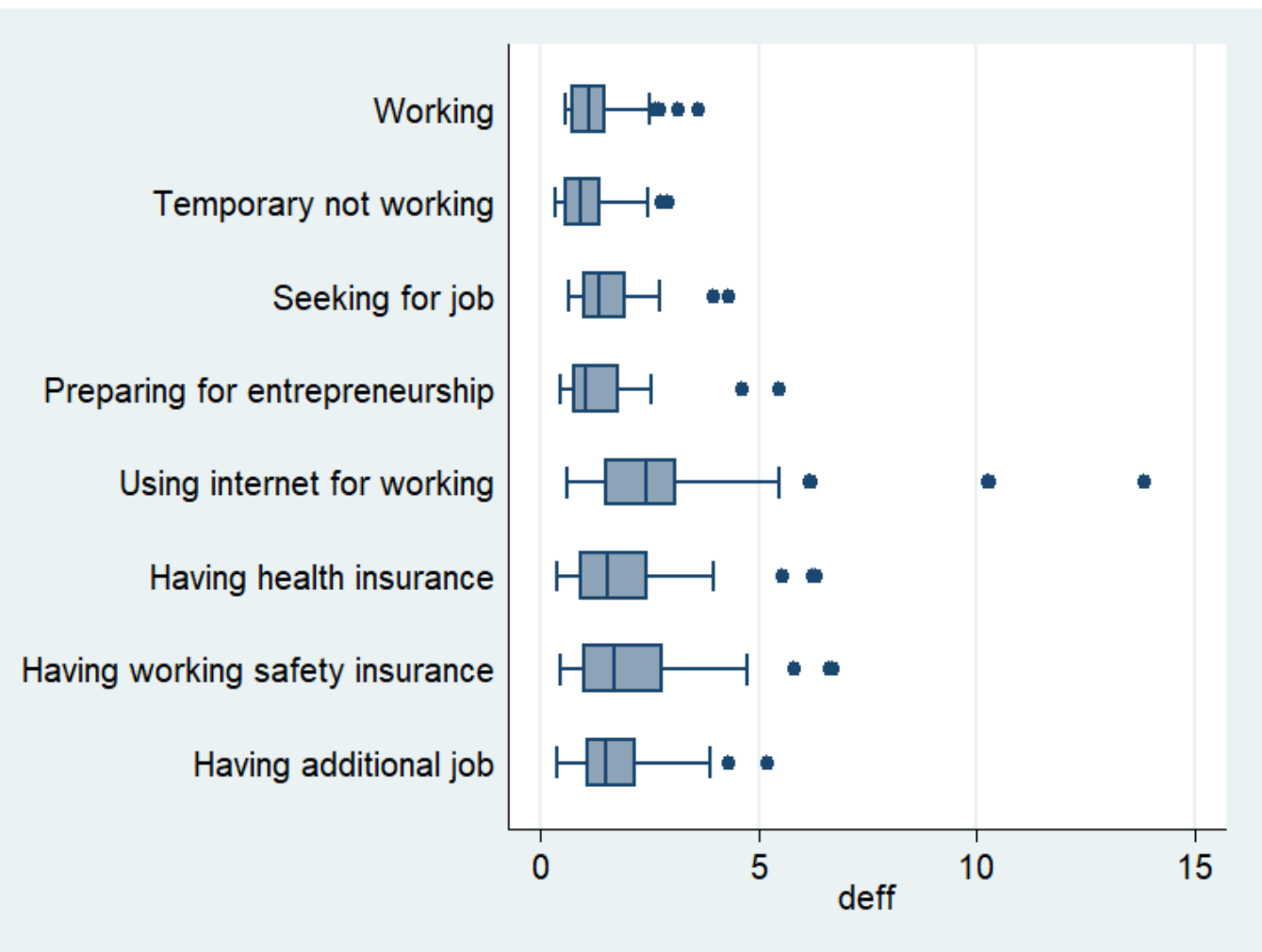

Figure 1: Boxplot of design effect due to clustering for province level estimation.

The boxplot in Figure 1 is resulted from the estimation at province level. Visualisation using boxplot aims to examine the range of design effect between provinces for each variable. In general, the pattern of design effect between provinces is not similar indicated by the range of design effect from those eight variables that is quite large. This finding is similar to the previous study in 7 developing countries that showed the difference of rate of homogeneity pattern across countries for estimating socioeconomic variables, while it is different from the previous study result of the design effect analysis for Demographic Health Survey. In other words, the rate of homogeneity of labour variables has similar pattern to the rate of homogeneity of socioeconomic variables. This is a logical finding because labour characteristics, intuitively are more correlated to socioeconomic variables than demographic variables.

The estimate of proportion people ages 15+ who work at least 1 hours per day continuously during 1 week and proportion of people ages 15+ who are temporary not working have a slight variation of design effect between provinces. On the other hand, more specific variable such as having insurance, having additional job, and using internet for working activities have large variation of design effect. There are also some provinces with outlier design effect values indicating that we should be more cautious to determine the sampling design for specific labour variables in those provinces. 
The high variation of design effect due to clustering across provinces gives valuable recommendation for survey design with province level estimation. It is inappropriate to use the rate of homogeneity value from another province to design survey in a particular province, or to use a single value of the rate of homogeneity at national level to determine the sample size for all provinces. We cannot assume that the rate of homogeneity is the same for all provinces. Thus, the assumption of design effect values for survey design should be different across provinces.

\subsection{Using design effect for designing the future survey}

Looking at Table 4, the effect of clustering is more dominant than the effect of sample weight, except for 2 variables: working and temporary not working. In addition, the ratio in urban area is higher than the ratio in rural area for 7 out of 8 variables. It means that the effect of clustering to in urban area are more dominant than in rural area. At national level, the ratio of clustering effect and weighting effect are less than 2 (except for estimating the proportion of people ages $15+$ using internet for working).

Table 4: Overall design effect and the ratio of clustering effect to weighting effect

\begin{tabular}{|c|c|c|c|c|c|c|c|}
\hline \multirow{2}{*}{ No } & \multirow{2}{*}{ Variable } & \multicolumn{3}{|c|}{$\begin{array}{l}\text { Overall design effect } \\
\left(\text { Deff }=\text { Deff }_{W} \times \text { Deff }_{C L}\right)\end{array}$} & \multicolumn{3}{|c|}{$R=\frac{\operatorname{Deff}_{C L}}{\operatorname{Deff}_{W}}$} \\
\hline & & urban & rural & national & urban & rural & national \\
\hline 1 & Working & 2.38 & 2.03 & 2.23 & 1.08 & 1.00 & 0.98 \\
\hline 2 & Temporary not working & 1.85 & 1.67 & 1.77 & 0.84 & 0.82 & 0.78 \\
\hline 3 & $\begin{array}{l}\text { Looking for job } \\
\text { Preparing for }\end{array}$ & 2.85 & 2.52 & 2.72 & 1.30 & 1.24 & 1.19 \\
\hline 4 & entrepreneurship & 3.40 & 1.92 & 2.93 & 1.54 & 0.95 & 1.28 \\
\hline 5 & Using internet for working & 7.48 & 3.65 & 6.26 & 3.40 & 1.79 & 2.74 \\
\hline 6 & $\begin{array}{l}\text { Having health insurance } \\
\text { Having work accident }\end{array}$ & 4.27 & 2.62 & 3.74 & 1.94 & 1.29 & 1.64 \\
\hline 7 & insurance & 4.36 & 2.71 & 3.86 & 1.98 & 1.33 & 1.69 \\
\hline 8 & Having additional job & 3.09 & 3.15 & 3.07 & 1.40 & 1.55 & 1.34 \\
\hline
\end{tabular}

The overall design effect is very important information to design the future survey. It is utilized to calculate the minimum sample size. For instance, we want to design a minimum sample size for estimating the proportion of people ages 15+ looking for job at national level using two stage stratified design with urban-rural stratification. Using information provided in Table 4, the minimum sample size is determined by $n=n_{\text {srs }} \times$ Deff $=2.72 \times n_{\text {srs }}$

where $n_{\text {srs }}$ is the minimum sample size assuming sample is selected using simple random sampling or SRS design, that can be defined as

$$
n_{\text {srs }}=\frac{Z_{\alpha / 2}^{2} P(1-P)}{(e P)^{2}} \times \frac{1}{k} \times \frac{1}{\bar{x}} \times \frac{1}{r}
$$

where $P$ is the proportion of people ages $15+$ looking for job from previous survey, $e$ is 
the percentage of margin of error determined, $k$ is the proportion of people ages 15+ to all population, $\bar{x}$ is the average number of people per household, and $r$ is the response rate.

If we are interested in estimating this variable at urban-rural level, the overall sample size will be higher because we have to calculate the minimum sample size per domain. It can be illustrated as

$n_{u}=n_{(s r s, u)} \times \operatorname{Deff}_{(u)}=2.85 \times n_{(s r s, u)}$

$n_{r}=n_{(s r s, r)} \times \operatorname{Deff}_{(r)}=2.52 \times n_{(s r s, r)}$

$n=n_{u}+n_{r}$

where $n_{u}$ is the minimum required sample size in urban area, $n_{(s r s, u)}$ refers to the minimum sample size in urban area assuming SRS design, $n_{r}$ is the minimum required sample size in rural area, and $n_{(s r s, r)}$ refers to the minimum sample size in rural area assuming SRS design.

\section{Conclusion}

In general, the design effect varies between labour variables in the range between 1.77 and 6.26 for estimation at national level. The rate of homogeneity is between 0.019 and 0.349. The effect of clustering, in general, is higher than the effect of sample weight. There is high variability of the clustering effect between provinces, whereas the effect of sample weight between provinces are similar. In addition, for estimation at stratum level, there are quite high differences of clustering effect between urban area and rural area. Similarly, the effect of sample weight in urban area also differs significantly from the effect of sample weight in rural area.

The high design effect of using internet for working variable due to clustering suggests that for the future specific survey related to this variable, the strategy to minimize the effect of clustering is to increase the sample size of cluster (census block) and to decline the sample size of households per cluster. On the other hand, to decrease the effect of sample weight for future survey, particularly in urban area, we can adjust the sample size to be more proportionally allocated to each stratum.

\section{References}

Cochran, W. G., \& William, G. (1977). Sampling Techniques. New York: John Wiley\& Sons. Inc.

Kalton, G. (1979). Ultimate cluster sampling. Journal of the Royal Statistical Society: Series A (General), 142(2), 210-222.

Kalton, G., Brick, J. M., \& Lê, T. (2005). Chapter VI Estimating components of design effects for use in sample design.

Kish, L. (1995). Survey sampling (Vol. 60). Wiley-Interscience. 
Mecatti, F. (2014). Sampling elusive populations: Applications to studies of child labour by Vijay Verma, 2013 International Labour Organization, Department of StatisticsGeneva: ILO. Sampling Elusive Populations: Applications to Studies of Child Labour by Vijay Verma, 2013 International Labour Organization, Department of Statistics-Geneva: ILO., 113-114.

Park, I., \& Lee, H. (2006). Design effects for the weighted mean and total estimators under complex survey sampling. Quality Control and Applied Statistics, 51(4), 381384.

Pettersson, H., \& Silva, P. (2005). Analysis of design effects for surveys in developing countries. Household Sample Surveys in Developing and Transition Countries, 123-143.

Verma, V., \& Lê, T. (1996). An analysis of sampling errors for the demographic and health surveys. International Statistical Review/Revue Internationale de Statistique, 265-294.

Verma, V., Scott, C., \& O'Muircheartaigh, C. (1980). Sample designs and sampling errors for the World Fertility Survey. Journal of the Royal Statistical Society: Series A (General), 143(4), 431-463. 